\title{
The clinical study on conservative therapy of pediatric intussusception: caudal block improves the success rate
}

\author{
Jong-Nam Kim, Chan Kim, Gum-Sun Choe, Hyon-Nam Kim \\ Department of Anesthesia and Resuscitation, Pyongyang Medical College, Kim Il Sung University, Pyongyang, Democratic People's Republic of \\ Korea \\ Contributions: (I) Conception and design: JN Kim; (II) Administrative support: GS Choe; (III) Provision of study materials or patients: C Kim; (IV) \\ Collection and assembly of data: HN Kim; (V) Data analysis and interpretation: C Kim; (VI) Manuscript writing: All authors; (VII) Final approval of \\ manuscript: All authors. \\ Correspondence to: Jong-Nam Kim. Department of Anesthesia and Resuscitation, Pyongyang Medical College, Kim Il Sung University, Central \\ District, Pyongyang, Democratic People's Republic of Korea. Email: pmed2@ryongnamsan.edu.kp.
}

\begin{abstract}
Background: Intestinal intussusception is one of diseases in which pediatric patient complain of acute abdominal pain and its morbidity is high. Therefore, it is necessary to diagnose and treat it swiftly but there are several difficulties for its treatment. Recently, there are many study and success for researching diagnosis and treatment of acute abdominal pain. Etiology and pathophysiology of intussusception are revealed so that non-invasive treatment is applied in clinical field. This study objective is to establish method of caudal block for treatment of pediatric intussusception and reveal the efficacy of this method.

Methods: A total of 124 pediatric patients received classical treatment for repair of intestinal intussusception; 42 patients received anesthesia by only ketamine intramuscularly in control group, whereas 82 patients received caudal block in combination with basal ketamine anesthesia in study group.

Results: Repair times of the classical method for pediatric intussusception by caudal block were $1.7 \pm 0.62$ times in study group and 2.6 \pm 0.38 times in control group, respectively. The necessary time and success rate for repair were $19.7 \pm 3.87 \mathrm{~min}$ and $93.9 \%$ in study group and $28.1 \pm 18.47 \mathrm{~min}$ and $85.7 \%$ in control group, respectively.

Conclusions: Caudal block in combination with intramuscular ketamine is very effective one that can raise the success rate $(93.9 \%)$ for repair as well as shorten repair times and necessary time.
\end{abstract}

Keywords: Pediatric intussusception; basal ketamine anesthesia; caudal block

Received: 07 November 2019; Accepted: 28 May 2020; Published: 25 August 2020.

doi: 10.21037/aos-19-16

View this article at: http://dx.doi.org/10.21037/aos-19-16

\section{Introduction}

Intussusception is the most cause of obstruction in infants, with an incidence of 2 to 4 for 1,000 live births (1). It is the result of the invagination of the bowel into an adjacent lower segment, usually at the terminal ileum or ileocecal valve, and rarely caused by polyp or Meckel diverticulum (5\% of cases). With time, intussusception leads to venous obstruction and bowel edema, which obstruct and compromise vascularity. The result of this process is a gangrenous bowel. The first signs are often paroxysmal pain, bloody diarrhea (often described as a currant jelly stool) and later vomiting (Figure 1). Therefore, it is very important to reduce an intussusception as soon as possible before complication brings about. In children with stable medical conditions, sedation is appropriate to facilitate reduction of the intussusception. This must be done cautiously with adequate resuscitative equipment and appropriate personnel nearby (2). But intramuscular or intravenous sedation do not provide enough relaxation to reduce an intussusception manually. A caudal block is commonly used to provide intra- and postoperative analgesia in children (3). 


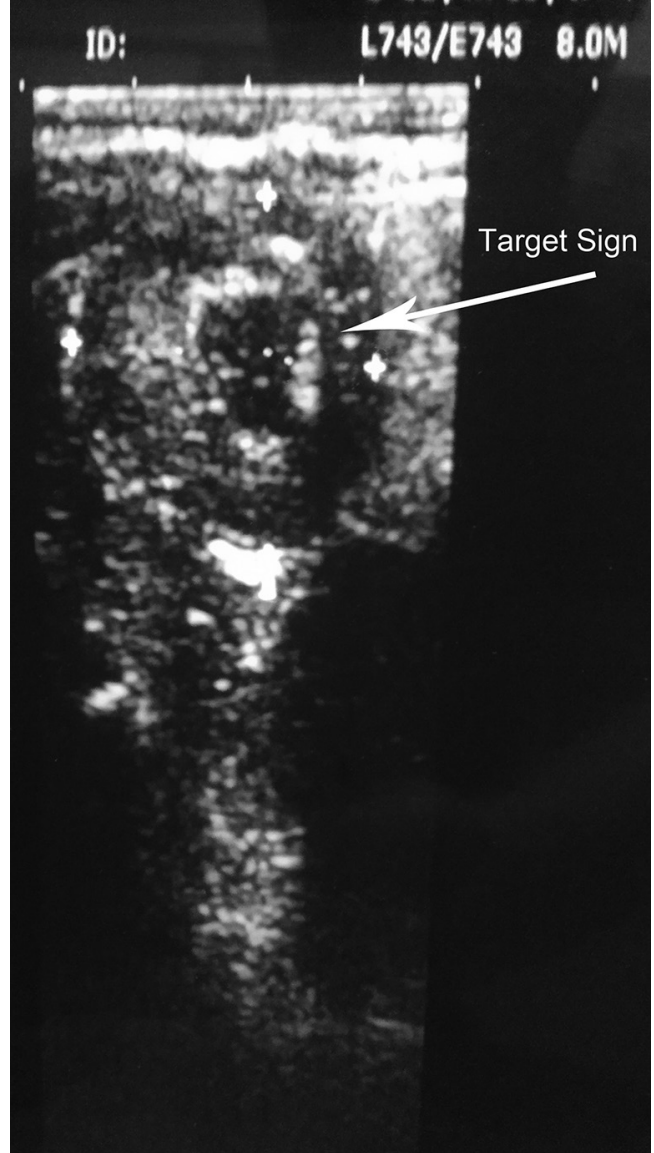

Figure 1 US image in pediatric intussusception before manual reduction.

A caudal block in combination with light sedation can support a good condition for reduction of intussusception in pediatric patients by relaxing abdominal muscle. Barium or air enemas are not only helpful in making the diagnosis but may also be therapeutic. In over $80 \%$ of cases, enema is successful in reducing the intussusception and if initially unsuccessful, repeat air enema is described in certain closely observed patients $(2,4)$. Under the successful caudal block, massage on abdominal region is also able to reduce mild or even moderate intussusception. This needs enough muscle relaxation to perform maneuver. We planned this study to evaluate whether the caudal block improves the condition for reduction of intussusception.

\section{What is already known?}

In children with stable medical conditions, sedation facilitates reduction of the intussusception.

\section{What new information this study adds}

Caudal block in combination with sedation can improve the condition for reduction of intussusception by providing sufficient muscle relaxation.

\section{Methods}

\section{Patients}

This randomized, double-blinded study was conducted after approval by the institutional research and ethics committee in Pyongyang Medical College Hospital of Kim Il Sung University between January 2006 and August 2010. Informed consent from patients was written. Our study contained 124 pediatric patients, age of six months to one year, ASA I-II who received classical and manual repair for intestinal intussusception. Of these patients 42 patients received anesthesia by only ketamine intramuscularly in control group (group K), whereas 82 patients received caudal block in combination with basal ketamine anesthesia in study group (group C). All patients were divided into two groups randomly. Children with reactive airway disease or a history of an upper respiratory tract infection (URI) in the preceding 3 weeks were excluded. In addition, patients were excluded from this study if there were contraindications to caudal block or lack of parental consent. Data were collected from beginning of caudal block to awakening of patients.

\section{Study protocol}

On arrival in operating room standard monitoring (ECG, $\mathrm{SpO}_{2}$, and noninvasive blood pressure) was applied. Patients in study group (group C) received preoperative sedative medication by atropine $0.1 \mathrm{mg}+0.01 \mathrm{mg} / \mathrm{kg}$, diphenhydramine $1.0 \mathrm{mg} / \mathrm{kg}$, ketamine $4 \mathrm{mg} / \mathrm{kg}$ intramuscularly a $15 \mathrm{~min}$ before operation. Patients in control group (group K) were given intramuscular ketamine $7-8 \mathrm{mg} / \mathrm{kg}$.

After checking sacral hiatus in the study group (group K), sterilization was performed on skin by using $3 \%$ iodine and $75 \%$ alcohol.

In the study group (group C), the caudal block was used. The sacral cornua and hiatus were palpated for the exact injection site in the lateral decubitus position. The anesthesiologist then penetrated the skin over the sacrococcygeal ligament midway between the cornua with a 1.5-2 inch, 21-gauge short-bevel needle (Figure 2). The 


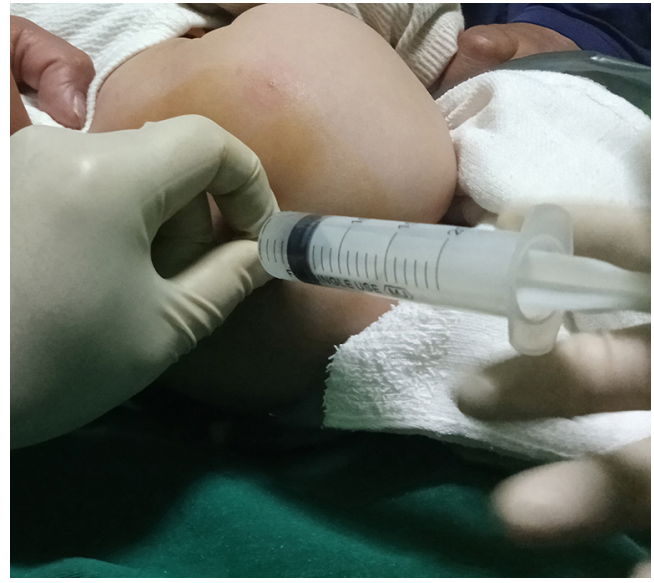

Figure 2 Caudal block technique.

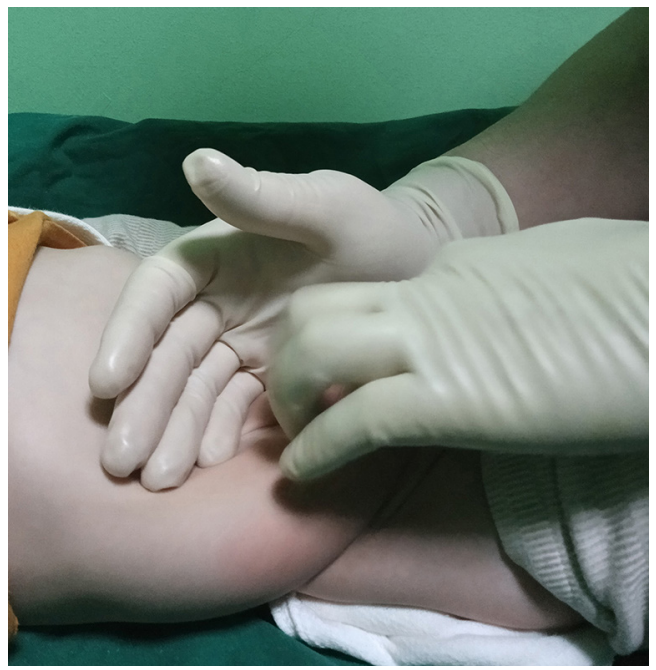

Figure 3 Manual reduction technique to intestine intussusception.

needle was inserted at a $60-90^{\circ}$ to skin surface and advanced until a 'pop' (piercing the sacrococcygeal ligament) was felt, then lowered to a $20-30^{\circ}$ angle to the skin and advanced an additional 2-3 $\mathrm{mm}$ into the sacral canal. After confirming that cerebrospinal fluid or blood could not be aspirated or free flowing from the needle, a test dose of $0.8-1 \mathrm{~mL} \cdot \mathrm{kg}^{-1}$ of local anesthetic (1\% lidocaine) was injected under hemodynamic and ECG monitoring. Following a negative test result, the rest LA was injected slowly over $1 \mathrm{~min}$ with little resistance. If the needle tip touched bone, or if there was a bloody puncture or subcutaneous bulging occurred, the needle was reinserted at an angle slightly different to the original angle. Following this, patients were turned into the supine position.

After dermatomal level was tested by pinprick method (no movements response to cutaneous pinprick) 15 min after LA injection, manual repair (massage along with running direction of large intestine) was performed. A successful block was defined as no motor or hemodynamic response (as indicated by the absence of an increase in mean arterial pressure or HR of more than $15 \%$ compared with baseline values obtained just before the incision) to massage maneuver. Otherwise, the block was considered a failure, in which case additional intravenous anesthetics injection was performed. In all patients $\mathrm{HR}, \mathrm{BP}$, and $\mathrm{SpO}_{2}$ were monitored continuously and recorded at 5 min intervals.

In group $\mathrm{K}$, pediatric patients were anesthetized by intramuscular ketamine $7-8 \mathrm{mg} / \mathrm{kg}$. Then the same manual maneuver was performed as in group C.

\section{Maneuver for repair of intestinal intussusception}

If all patients could not response to nociceptive stimulation, maneuver for repair of intussusception was performed. Operator for repair placed his/her right hand vertically on patient's abdominal wall and moved his/her left hand counterclockwise along with large intestine so that pressure pushed intussuscepted small intestine (Figure 3). Additionally, high level of intestinal irrigation was carried out by using $3 \%$ soap solution. At this time, once gurgling sound was heard, intussusception might be repaired followed by checking using ultrasonography which showed loss of globus sign (Figure 1).

If repair succeed, patients entered recovery room until wake up followed by discharge from hospital (Figure 4).

\section{Measurement and data collected}

In order to assess the efficacy of caudal block, quality of analgesia was estimated by onset, level and effect. Analgesia effect was evaluated as good, moderate, poor according to movement of patient and ease of repair. We considered the awareness onset time to be the time when pediatric patient was responsible to noxious stimulation and all reflexes were recovered. As well as, patient was considered awaked when he/she was going to suck his/her mother's nipple. Parameters such as times of manual repair, success rate, wasting time were comparable between two groups. Patient's vital signs were obtained from standard monitoring every 5-10 minutes at premedication, postanesthesia, postrepair. 


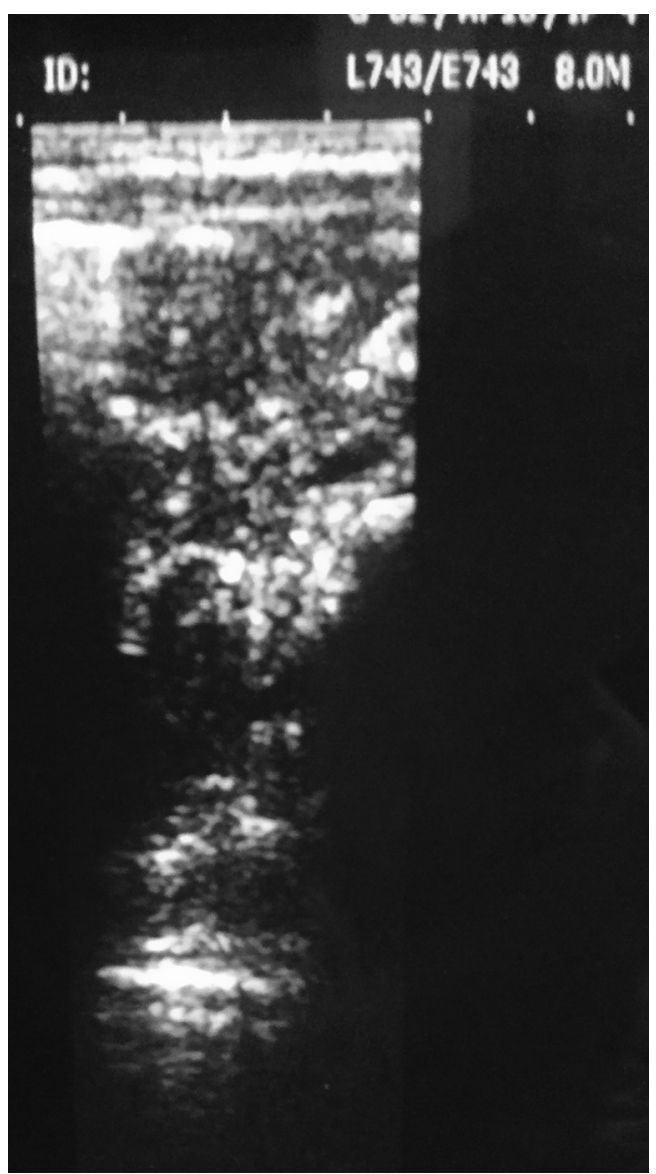

Figure 4 US image after reduction of intussusception.

Table 1 Patient's characteristics and relevant data

\begin{tabular}{lll}
\hline Variable & Group K & Group C \\
\hline Male/female & $27 / 15$ & $56 / 26$ \\
Age (months) & $8.02(6.0-13.0)$ & $7.07(5.5-12.8)$ \\
Weight $(\mathrm{kg})$ & $9.3(4.0-18.0)$ & $8.5(3.8-19.5)$ \\
Period from onset to & $16.83 \pm 7.83(\mathrm{n}=42)$ & $16.76 \pm 8.42(\mathrm{n}=82)$ \\
admission & & \\
Vital signs before procedure & $110 \pm 10.8$ & $109 \pm 12.6$ \\
SBP & $69.6 \pm 8.79$ & $68.2 \pm 1.02$ \\
DBP & $120.4 \pm 2.82$ & $121.6 \pm 26.5$ \\
HR & $32.1 \pm 7.63$ & $36.1 \pm 11.0$ \\
RR & & \\
\hline
\end{tabular}

All data were analyzed by using $\chi^{2}$ test and test and evaluated as significant value if $\mathrm{P}$ was less than 0.05 .

\section{Results}

\section{Demographic data}

All patient's characteristics were compared between two groups (Table 1). There were no differences between two groups by means of patient's characteristics, period from onset of symptom to admission in hospital, vital signs before procedure [systolic blood pressure (SBP), diastolic blood pressure $(\mathrm{DBP})$, heart rate $(\mathrm{HR})$, respiratory rate $(\mathrm{RR})]$.

\section{Efficacy of anesthesia}

The onset time of analgesia were $6.9 \pm 1.32 \mathrm{~min}$ in the group $\mathrm{C}, 28.7 \pm 2.30 \mathrm{~min}$ in the group $\mathrm{K}$, respectively $(\mathrm{P}<0.05)$. The good efficacy of analgesia was $77(83.9 \%)$ cases in the group C, $32(76.2 \%)$ cases in the group $\mathrm{K}$, respectively $(\mathrm{P}<0.05)$.

In the group C, $1 \%$ lidocaine of $1 \mathrm{~mL} / \mathrm{kg}$ blocked 33 cases to Th10 level, and 22 cases in the group $\mathrm{K}$, respectively. Therefore, there was significant difference in blocked level as volume of local anesthetics increase. The relaxation of abdominal muscle were 78 cases $(95.1 \%)$ in the group C, 15 cases $(35.7 \%)$ in the group $\mathrm{K}$, respectively $(\mathrm{P}<0.05)$. The respiration rate decreased markedly after premedication. While repair performed, there was no changes of respiration rate in the group C. In the group $\mathrm{K}$, there was marked rise of respiration rate than before premedication. Changes in $\mathrm{SpO}_{2}, \mathrm{HR}, \mathrm{SBP}$ and DBP did not occur during repair.

The frequency of complications is as shown in Table 2.

\section{Effect of anesthesia to manual repair of intussusception}

The time for starting repair was $15.8 \pm 11.94 \mathrm{~min}, 20.2 \pm 13.75$ min in group $C$ and $K$, respectively $(\mathrm{P}<0.05)$. The frequency of manual operation was $1.7 \pm 0.62$ times, $2.6 \pm 0.38$ times in group $\mathrm{C}$ and $\mathrm{K}$, respectively, so there was significant difference between both groups $(\mathrm{P}<0.05)$. The time from beginning repair to end was considered into spending time for repair, $19.7 \pm 3.87 \mathrm{~min}, 28.1 \pm 18.47 \mathrm{~min}$ in group $\mathrm{C}$ and group $\mathrm{K}$, respectively, with significant difference. Success 
Table 2 Complication during anesthesia (case)

\begin{tabular}{lll}
\hline Variable & Group K & Group C \\
\hline Hypotension & Nil & 1 \\
Total spinal anesthesia & Nil & Nil \\
Respiratory depression & 2 & Nil \\
Reflux & 3 & 1 \\
Intestinal perforation & Nil & Nil \\
Urinary retention & Nil & Nil \\
Sensory impairment & Nil & Nil \\
\hline
\end{tabular}

rate of this technique was $93.9 \%, 85.7 \%$ in group $\mathrm{C}$ and $\mathrm{K}$, respectively.

\section{Discussion}

Our study shows that caudal block facilitates the repair of intestinal intussusception with less complication and negative effects on human body. Barium or air enemas are not only helpful in making the diagnosis but may also be therapeutic (4). Massage is also able to be helpful in repairing intussusception. But most of infants are uncooperative, so sedation or anesthesia is necessary to apply these techniques. In children with stable medical conditions, sedation is appropriate to facilitate reduction of the intussusception. This must be one cautiously with adequate resuscitative equipment and appropriate personnel nearby $(5,6)$. The very deep sedation can bring about respiratory complication, as well as require expensive medication. Caudal block is one of the most popular nerve blocks in children, but has never been used for intussusception treatment. Children less than age of two are involved in our study because intussusception occurred frequently of these age group. We applied caudal block for intussusception repair of children who are ill with abdominal pain within 24 hrs. Meier et al. noted that patients with a long duration of symptoms and/or suspected bowel perforation may need to proceed directly to surgery (7). Our study also excluded patients with suspicion of perforation and arrived to hospital in 30 hrs. With respect to local signs in abdomen, there occurred intermediate tympanites and aerenterectasia from 12 hrs after onset, muscular defense from 14 hrs after onset, 4 cases of peritonitis from $24 \mathrm{hrs}$ after onset. This showed that manual reduction can be performed within $24 \mathrm{hrs}$, which corresponded with the results that initial abdominal pain leaded to facial changes with systematic symptom $(8,9)$. As noted above, sedation or anesthesia helps the reduction of intussusception. Ketamine was most widely used for basal anesthesia in various interventional treatment to pediatric patient, especially by intramuscular ketamine in combination with drying agent, such as atropine, glycopyrrolate. We used intramuscular atropine for preoperative drying. Intramuscular ketamine was administered into $7-8 \mathrm{mg} / \mathrm{kg}$, $4 \mathrm{mg} / \mathrm{kg}$ in group $\mathrm{K}$ and group $\mathrm{C}$, respectively. The reason why smaller dose of ketamine was injected in group $C$ than group $\mathrm{K}$ is because of assumption that caudal block can decrease the dose of ketamine necessary for reduction of intussusception. Lidocaine is a local anesthetic that has the intermediate duration, which is used for short procedure. Ivani et al. investigated three different concentrations of caudal levobupivacaine $(0.125 \%, 0.20 \%$, and $0.25 \%)$ in a prospective, randomized, observer-blinded study in children (1 to 7 yrs of age) undergoing infraumbilical surgery (10). In our study, lidocaine was used for reduction of intussusception because the time necessary for procedure was usually short. The onset time of analgesia was $6.9 \pm 1.32$ $\min , 28.7 \pm 2.3 \mathrm{~min}$ in the group $\mathrm{C}$ and $\mathrm{K}$, respectively. So time in group $\mathrm{C}$ was markedly shorter than group $\mathrm{K}$, although procedure began $15 \mathrm{~min}$ after intramuscular ketamine injection. This might be because onset time of lidocaine was short as well as anesthesia was performed in combination with ketamine. In prior literature, it was mentioned that epidural block higher than Th4 decreased blood pressure, cardiac output and contractility of heart muscle due to depression of myocardial activity by local anesthetics (11). Our study showed that caudal block by $1 \%$ lidocaine was safe hemodynamically for reduction of intussusception. Regional anesthesia may not influence emergence and have a good analgesia. In our study, awake time in group $\mathrm{C}$ and $\mathrm{K}$ was $37.28 \pm 11.53 \mathrm{~min}, 49.28 \pm 11.53$ min, respectively, therefore time in group $\mathrm{C}$ was still shorter than group $\mathrm{K}$. This might be due to using less dose of ketamine in group $\mathrm{C}$ than group $\mathrm{K}$. The complications result from misplacement of the needle into the superficial soft tissues, or intravascular, intraosseous and intrathecal injections leading to technique failure, systemic toxicity, or spinal anesthesia (12-15). But there was no neurological complication but hemodynamic, respiratory and digestive 
one, such as hypotension, respiratory depression, reflux in our study. There was 1 case of hypotension in group C, 2 cases of respiratory depression in group $\mathrm{K}, 1$ case and 3 cases of reflux in group $\mathrm{C}, \mathrm{K}$ respectively and no intestinal perforation, sensory impairment and urinary retention. We analyzed the efficacy of caudal block to reduction of intussusception with manual operation frequency, the time for starting repair, the time from beginning repair to end and success rate of reduction. The time for starting repair was $15.8 \pm 11.94 \mathrm{~min}, 20.2 \pm 13.75 \mathrm{~min}$ in group $\mathrm{C}$ and $\mathrm{K}$, respectively $(\mathrm{P}<0.05)$. We did not find the previous literature about time for beginning repair. The time of onset and for starting repair was different in both groups because manual operation could perform only when both analgesia and muscle relaxation provided. In the group C, starting repair was faster than in the group $\mathrm{K}$, which means that muscle relaxation in the group $\mathrm{C}$ was better than group $\mathrm{K}$. This may be due to motor block by caudal block. Researchers recommended that conservative therapy was crucial to reduce the intussusception in pediatric patients, but treatment rate was lowered as time went by $(16,17)$. The frequency of manual operation was $1.7 \pm 0.62$ times, $2.6 \pm 0.38$ times in group $\mathrm{C}$ and $\mathrm{K}$, respectively. The longer course of disease was, the more frequent times of reduction. We assumed that this was because pathological changes such as fibrin precipitation, edema and swelling occurred on local site of bowel. The time from beginning repair to end was considered into spending time for repair, $19.7 \pm 3.87 \mathrm{~min}$, $28.1 \pm 18.47 \mathrm{~min}$ in group C and group $\mathrm{K}$, respectively, with significant difference. Success rate of this technique was 93.9\%, $85.7 \%$ in group $\mathrm{C}$ and $\mathrm{K}$, respectively. The reason why higher success rate in group $\mathrm{C}$ than group $\mathrm{K}$ may be because the caudal block improved the blood circulation of bowel and muscle relaxation, leading to advantageous situation for reduction of intussusception due to strong peristalsis.

\section{Conclusions}

The caudal block in combination with ketamine improved the success rate (approximately 93.9\%) of reduction of intussusception and shorten the necessary time for reduction as well as did not affect a negative effect on the hemodynamic and respiratory function.

\section{Acknowledgments}

Funding: None.

\section{Footnote}

Conflicts of Interest: All authors have completed the ICMJE uniform disclosure form (available at http://dx.doi. org/10.21037/aos-19-16). The authors have no conflicts of interest to declare.

Ethical Statement: The authors are accountable for all aspects of the work in ensuring that questions related to the accuracy or integrity of any part of the work are appropriately investigated and resolved. The study was approved by Pyongyang Medical College Hospital Ethic Review Committee.

Open Access Statement: This is an Open Access article distributed in accordance with the Creative Commons Attribution-NonCommercial-NoDerivs 4.0 International License (CC BY-NC-ND 4.0), which permits the noncommercial replication and distribution of the article with the strict proviso that no changes or edits are made and the original work is properly cited (including links to both the formal publication through the relevant DOI and the license). See: https://creativecommons.org/licenses/by-nc-nd/4.0/.

\section{References}

1. DiFiore JW. Intussusception. Semin Pediatr Surg 1999;8:214-20.

2. Elliott ST, Sandler AD. Digestive Tract Procedures: Surgical Considerations. Pediatric Anesthesia, PMPHUSA, 2011;1505:1525-6.

3. Blaise G, Roy WL. Postoperative pain relief after hypospadias repair in pediatric patient: regional analgesia versus systemic analgesics. Anesthesiology 1986;65:84-6.

4. Sandler AD, Ein SH, Connolly B, et al. Unsuccessful airenema reduction of intussusception: is a second attempt worthwhile? Pediatr Surg Int 1999;15:214.

5. Murat I, Delleur MM, Levy J, et al. Continuous epidural anaesthesia for major abdominal surgery in young children. Eur J Anaesthesiol 1987;4:327-35.

6. Kokoska ER, Silen ML, Tracy TF Jr, et al. The impact of intraoperative culture on treatment and outcome in children with perforated appendicitis. J Pediatr Surg 1999;34:749-53.

7. Meier DE, Coln CD, Rescorla FJ, et al. Intussusception in children: international perspective. World J Surg 1996;20:1035.

8. Rosenfeld K, McHugh K. Survey of intussusception 
reduction in England, Scotland and Wales: how and why we could do better. Clin Radiol 1999;54:452-8.

9. Fragoso AC; Pneumatic reduction of childhood intussusception. Is prediction of failure important? J Pediatr Surg 2007;42:1504-8.

10. Ivani G, De Negri P, Lonnqvist PA, et al. A comparison of three different concentrations of levobupivacaine for caudal block in children. Anesth Analg 2003;97:368-71.

11. Raux O. Pediatric caudal anaesthesia. Anaesthesia Update 2010.

12. Dalens BJ. Regional anesthesia in children. In: Miller RD. editor. Miller's Anesthesia, 6th edn. Philadelphia: Churchill Livingstone, 2005:1733-4.

13. Jöhr M, Berger TM. Caudal blocks. Paediatr Anaesth

doi: $10.21037 /$ aos-19-16

Cite this article as: Kim JN, Kim C, Choe GS, Kim HN. The clinical study on conservative therapy of pediatric intussusception: caudal block improves the success rate. Art Surg 2020;4:1.
2012;22:44-50.

14. Dalens B, Hasnaoui A. Caudal anesthesia in pediatric surgery: success rate and adverse effects in 750 consecutive patients. Anesth Analg 1989;68:83-9.

15. Afshan G, Khan FA. Total spinal anaesthesia following caudal block with bupivacaine and buprenorphine. Paediatr Anaesth 1996;6:239-42.

16. Abantanga FA. Ileal invagination of the sigmoid colon producing a sigmoi dorectal intussusception combined with rectal prolapse in a 3 -year-old child. Pediatr Surg Int 2005;21:400-2.

17. Krishnakumar. Ultrasound Guided Hydrostatic Reduction in the Management of Intussusception. Indian Journal of Pediatrics 2002;73:45-8. 